\title{
OPEN COVID-19 vaccine acceptance among adults in four major US metropolitan areas and nationwide
}

\begin{abstract}
Ayman El-Mohandes ${ }^{1}$, Trenton M. White ${ }^{2}$, Katarzyna Wyka ${ }^{1}$, Lauren Rauh ${ }^{1}$, Kenneth Rabin ${ }^{1}$, Spencer H. Kimball ${ }^{3}$, Scott C. Ratzan ${ }^{1} \&$ Jeffrey V. Lazarus ${ }^{2}$

This study assesses attitudes towards COVID-19 vaccination and the predictive value of COVID-VAC, a novel scale, among adults in the four largest US metropolitan areas and nationally. A 36-item survey of 6037 Americans was conducted in mid-April 2021. The study reports factors for COVID-19 vaccine acceptance among: (1) already vaccinated; (2) unvaccinated but willing to accept a vaccine; and (3) unvaccinated and unwilling to vaccinate. More than $20 \%$ were unwilling to vaccinate, expressing concerns about vaccine efficacy and safety and questioning the disease's severity. Poverty, working outside of the home and conservative political views are predictors of unwillingness. Conversely, those who either personally tested positive for COVID-19, or had a family member who did so, were more likely to accept vaccination. Majorities of all respondents supported vaccination mandates for employees and university students. Respondents preferred to receive vaccines in their doctor's office. Lower income and conservative ideology, but not race, were strongly associated with vaccine unwillingness. The predictive value of COVID-VAC was demonstrated. While vaccination mandates are likely to be accepted, additional effective, targeted interventions to increase vaccine uptake are needed urgently.
\end{abstract}

The COVID-19 pandemic continues to threaten population health, disrupt healthcare delivery and diminish economic and social activities globally, with over 230 million cumulative cases, 4.7 million deaths, and 6.2 billion doses of administered vaccines ${ }^{1,2}$. In the United States (US), there have been $44,314,424$ reported COVID19 cases and 716,847 deaths as of 1 October 2021, the highest number of deaths of any country in the world ${ }^{3}$. COVID-19 vaccinations in the US started on 13 December 2020, and 392,909,995 doses have been administered to date; $184,601,450$ ( $55.5 \%$ of the population) are fully vaccinated ${ }^{4,5}$. Although $77 \%$ of American adults have now received at least one dose of a COVID-19 vaccine, trends indicate slowing rates and missing second shots ${ }^{4}$. New studies of evolving attitudes and opinions of Americans in different parts of the US who remain unwilling or uncertain about vaccination can contribute to strategic guidance for policymakers and healthcare providers.

Encouraging uptake of a COVID-19 vaccine among the remaining unvaccinated will largely depend on motivating those expressing a degree of vaccine hesitancy, defined by the WHO SAGE Working Group on Vaccine Hesitancy as the "delay in acceptance or refusal of vaccination despite availability of vaccination services ${ }^{6}$." Heterogenous beliefs and behaviours with respect to risk, health, and trust in authorities within and across countries influence individuals' decisionmaking about vaccines ${ }^{7}$. Major factors associated with vaccine hesitancy include perceptions on risk, safety, efficacy and trust, in addition to sociodemographic characteristics ${ }^{8-14}$. In the United States, COVID-19 vaccine hesitancy has been influenced by these identified factors ${ }^{15,16}$ as well as political factors ${ }^{14,17-19}$.

Only two formal studies of changing US attitudes towards COVID-19 vaccine acceptance were published over the first five months of vaccine availability ${ }^{20,21}$. Earlier research on willingness to vaccinate, conducted while the vaccines were in development, showed public confidence rising and falling based on factors such as media coverage, political identity and trust in public health authorities ${ }^{16,19,22-27}$, as well as trust in government ${ }^{28}$. A December 2020 rapid systematic review concluded that achieving herd immunity hinged on research-based strategies to communicate vaccine risks and benefits and to target politically, demographically, and socio-economically diverse groups across the US ${ }^{29}$. Since then, numerous polls have measured vaccine attitudes and factors impacting uptake. The Kaiser Family Foundation's monthly vaccine monitor confirmed that overall COVID-19 vaccine confidence

${ }^{1}$ Graduate School of Public Health \& Health Policy, City University of New York (CUNY), New York, NY, USA. 'Barcelona Institute for Global Health (ISGlobal), Hospital Clínic, University of Barcelona, Barcelona, Spain. ${ }^{3}$ Emerson College Polling, Emerson College, Boston, MA, USA. ${ }^{\circledR}$ email: jeffrey.lazarus@isglobal.org 
continued to rise as vaccinations rolled out. Amongst those uncertain or against a COVID-19 vaccine, no key sentiment or sub-group (e.g. political, socioeconomic, demographic) was monolithic ${ }^{30}$.

This study explores factors associated with vaccine acceptance in the US in 2021, one year after the pandemic was declared, including perceptions of risk, safety, efficacy and trust in government as well as sociodemographic and political factors. It also tests the predictive value of a novel 6-item vaccine acceptance scale, COVID-VAC. Respondents' motivators and barriers, preferred sources of information and vaccination location were explored to help inform vaccination strategies.

\section{Results}

Study population. The four US metropolitan areas had a higher percentage of racial and ethnic minority respondents than the national sample (Table 1, Supplemental Table S1). Educational levels (bachelor's degree and above) and income levels (US \$75,000 and above) were also higher in the metropolitan areas. In general, a higher percentage of respondents in the metropolitan areas worked outside the home than found in the national sample. While political views were represented in relatively equal proportions nationally, metropolitan areas with the exception of Dallas (22\%) had significantly fewer respondents with conservative views (13-17.2\%).

National and metropolitan area vaccination rates and intent to vaccinate. Vaccination rates were significantly $(P<0.001)$ higher in three metropolitan areas (Chicago, NY, LA) than either for Dallas or the national sample (Table 1). The top reasons to vaccinate were protection from COVID-19 for oneself (national 42.3\%, metropolitan areas 38.5-50\%; Table 2), or family and friends (national 30\%, metropolitan areas 24.4$33.5 \%$ ) and to "help end the pandemic" (national 23.4\%, metropolitan areas 19.7-25.5\%). More than a third of the respondents who had already received the vaccine said they encountered difficulties in making an appointment. The top reasons given were lack of proximity of available sites, or not knowing how to sign up for an appointment. Approximately half of the respondents not yet vaccinated still plan to do so. Of this group, a plurality indicated a preference for receiving the vaccine in their doctor's office compared to other sites. The majority of respondents who have been vaccinated or plan to do so felt confident the vaccine would protect against all variants of COVID-19 (Supplemental Table S6).

More than one-fifth (21.4\%) of the national respondents indicated an unwillingness to vaccinate (Table 1). With the exception of the Dallas metropolitan area (19.7\%), unwillingness to vaccinate was significantly lower in NY $(10.1 \%)$, LA $(11.5 \%)$, and Chicago $(11.2 \%)$ than the national average $(P<0.001)$. The main reason for unwillingness was "waiting to see if there are no serious complications" (Table 2). When asked what would increase their readiness to accept vaccination, almost half of those who expressed unwillingness said that "nothing would change their minds" (Table 2).

Unwillingness to vaccinate was significantly lower among respondents age 60 and older compared to younger respondents $(P<0.0001$; Table 3$)$ in the national sample, but was comparable among women and men, different racial groups and educational levels. Except in Dallas and Chicago, where findings were mixed, unwillingness to vaccinate was significantly greater among lower-income individuals $(P<0.001)$. Unwillingness was also uniformly greater among individuals with moderate $(25.5 \%)$ to conservative $(26.7 \%)$ political views, compared to political liberals $(10.9 \%)$, a trend that held across all metropolitan areas and the national sample $(P<0.0001)$. Unwillingness also correlated significantly with whether the respondent worked from home, worked outside the home or was unemployed $(P=0.007)$, and whether the individual or a household member had not received a positive test for COVID-19 in the past, compared to having tested positive $(P=0.001)$. Compared to similar respondents from the other three metropolitan areas, both White and Black residents of the Dallas metropolitan area were significantly less willing to vaccinate, as were those with less than a college degree $(P<0.001)$.

COVID-19 vaccine acceptance scale (COVID-VAC). The six-item vaccination acceptance scale, which contains items on perceptions of risk, trust, safety, and efficacy, was unidimensional and reliable. Its first component explained $62.8 \%$ of variance with the remaining factors having eigenvalues below 1 (Cronbach's alpha $=0.87$ ). The high vaccine acceptance score recorded on this scale indicates strong endorsement of the six statements about COVID-19 and vaccines. Individual scores correlated strongly with actual or planned vaccination nationally $(\mathrm{OR}=10.16 ; 95 \% \mathrm{CI} 7.01-14.71)$ and in the four metropolitan areas: $\mathrm{NY}(\mathrm{OR}=9.59 ; 95 \%$ CI 5.33-17.25), LA (OR=6.43; 95\% CI 3.13-13.23), Dallas $(\mathrm{OR}=12.18$; 95\% CI 7.55-19.16), and Chicago $(\mathrm{OR}=14.17 ; 95 \% \mathrm{CI}$ 6.65-30.20). Scores were stable across demographic groups classified by age, gender, race, education and income level (Supplemental Table S2).

The statement that "COVID-19 is a dangerous health threat" (Table 4) generated the highest degree of agreement (nationally $84 \%$, metropolitan areas $82.3-90.4 \%$ ). However, more than a quarter $(25.8 \%)$ of the national respondents did not believe that the dangers of COVID-19 exceed those of the vaccine, a level of skepticism found less frequently in the metropolitan areas. One in five (21.7\%) national sample participants also disbelieved that COVID-19 can be prevented by vaccination (metropolitan areas 15.6-19.3\%); more so among participants who reported holding conservative views (Supplemental Table S3). However, around three-fourths of responents did trust in the science behind the vaccines (72.9\% nationally, metropolitan areas $72.7-85.2 \%$, Table 4 ).

A slightly lower but still solid majority believed that COVID-19 vaccines would be distributed fairly "to everyone and everywhere" (69.6\% nationally, metropolitan areas $70.2-76.2 \%$, Table 4$)$. Greater doubts about fairness were found among those with lower incomes (35.7\%), worked outside the home (38.3\%), or did not state their political views (45.2\%). However, these factors showed no consistent associations across the metropolitan areas (Supplemental Table S3). 


\begin{tabular}{|c|c|c|c|c|c|c|c|c|c|c|c|c|c|c|}
\hline & \multirow{2}{*}{\multicolumn{2}{|c|}{ National }} & \multicolumn{12}{|c|}{ Metropolitan area } \\
\hline & & & \multirow{2}{*}{$\begin{array}{l}\mathrm{NY} \\
\mathrm{n}\end{array}$} & \multirow[b]{2}{*}{$\%$} & \multirow{2}{*}{$\begin{array}{l}\text { LA } \\
\mathrm{n}\end{array}$} & \multirow[b]{2}{*}{$\%$} & \multirow{2}{*}{$\begin{array}{l}\text { Dallas } \\
\mathbf{n}\end{array}$} & \multirow[b]{2}{*}{$\%$} & \multirow{2}{*}{\begin{tabular}{|l|} 
Chicago \\
$\mathbf{n}$ \\
\end{tabular}} & \multirow[b]{2}{*}{$\%$} & \multirow{2}{*}{\begin{tabular}{|l|} 
NY \\
$P$-value
\end{tabular}} & \multirow[t]{2}{*}{ LA } & \multirow[t]{2}{*}{ Dallas } & \multirow[t]{2}{*}{ Chicago } \\
\hline & $\mathbf{n}$ & $\%$ & & & & & & & & & & & & \\
\hline \multicolumn{15}{|l|}{ Age } \\
\hline $18-29$ & 402 & 19.9 & 207 & 20.5 & 225 & 22.5 & 230 & 23 & 209 & 20.8 & 0.997 & 0.929 & 0.032 & 0.976 \\
\hline $30-39$ & 349 & 17.3 & 181 & 17.9 & 188 & 18.7 & 203 & 20.3 & 183 & 18.2 & & & & \\
\hline $40-49$ & 333 & 16.5 & 168 & 16.7 & 163 & 16.2 & 190 & 18.9 & 170 & 16.9 & & & & \\
\hline $50-59$ & 341 & 16.9 & 168 & 16.7 & 163 & 16.3 & 162 & 16.2 & 170 & 16.9 & & & & \\
\hline $60-69$ & 301 & 14.9 & 142 & 14.1 & 138 & 13.8 & 122 & 12.2 & 144 & 14.3 & & & & \\
\hline $70+$ & 295 & 14.6 & 142 & 14.1 & 125 & 12.5 & 95 & 9.5 & 131 & 13 & & & & \\
\hline \multicolumn{15}{|l|}{ Sex } \\
\hline Male & 974 & 48.2 & 464 & 46 & 476 & 47.6 & 479 & 47.8 & 477 & 47.4 & 0.158 & 0.739 & 0.834 & 0.270 \\
\hline Female & 1012 & 50.1 & 504 & 50.1 & 496 & 49.6 & 499 & \begin{tabular}{|l|}
49.8 \\
\end{tabular} & 497 & 49.4 & & & & \\
\hline Prefer not to say/other & 34 & 1.7 & 39 & 3.9 & 28 & 2.8 & 24 & 2.4 & 32 & 3.2 & & & & \\
\hline Race & & & & & & & & & & & & & & \\
\hline White & 1221 & 60.4 & 448 & 44.5 & 291 & 29.1 & 453 & 45.2 & 519 & 51.6 & $<.0001$ & $<.0001$ & $<.0001$ & 0.151 \\
\hline Black & 248 & 12.3 & 159 & 15.8 & 60 & 6 & 161 & 16.1 & 160 & 15.9 & & & & \\
\hline Latino/a & 371 & 18.4 & 249 & 24.7 & 452 & 45.1 & 292 & 29.1 & 230 & 22.8 & & & & \\
\hline Asian & 109 & 5.4 & 110 & 10.9 & 161 & 16 & 70 & 7 & 70 & 6.9 & & & & \\
\hline Other & 70 & 3.5 & 150 & 14.9 & 41 & 4.1 & 26 & 2.6 & 28 & 2.8 & & & & \\
\hline Highest level of education & & & & & & & & & & & & & & \\
\hline High school degree or less & 772 & 38.2 & 379 & 37.6 & 390 & 39 & 364 & 36.4 & 349 & 34.7 & $<.0001$ & 0.310 & 0.491 & 0.117 \\
\hline Some college & 578 & 28.6 & 209 & 20.8 & 260 & 26 & 273 & 27.3 & 259 & 25.7 & & & & \\
\hline Bachelor's Degree & 410 & 20.3 & 239 & 23.8 & 230 & 23 & 233 & 23.2 & 239 & 23.8 & & & & \\
\hline Graduate degree or more & 259 & 12.8 & 179 & 17.8 & 120 & 12 & 132 & 13.1 & 160 & 15.8 & & & & \\
\hline Household income & & & & & & & & & & & & & & \\
\hline$<\$ 25,000$ & 303 & 15 & 150 & 14.9 & 148 & 14.8 & 112 & 11.2 & 103 & 10.2 & $<.0001$ & $<.0001$ & $<.0001$ & $<.0001$ \\
\hline$\$ 25,000-\$ 74,999$ & 889 & 44 & 322 & 31.9 & 374 & 37.4 & 351 & 35 & 308 & 30.6 & & & & \\
\hline$\$ 75,000-\$ 150,000$ & 500 & 24.7 & 241 & 23.9 & 238 & 23.8 & 295 & 29.4 & 258 & 25.7 & & & & \\
\hline$>\$ 150,000$ & 136 & 6.7 & 131 & 13 & 143 & 14.3 & 123 & 12.3 & 133 & 13.2 & & & & \\
\hline Prefer not to say & 192 & 9.5 & 164 & 16.3 & 98 & 9.8 & 121 & 12.1 & 205 & 20.3 & & & & \\
\hline Employment & & & & & & & & & & & & & & \\
\hline Working from home & 743 & 36.8 & 332 & 32.9 & 295 & 29.5 & 327 & 32.6 & 338 & 33.6 & 0.367 & 0.054 & $<.0001$ & 0.225 \\
\hline Working outside the home & 557 & 27.6 & 286 & 28.4 & 365 & 36.4 & 412 & 41.1 & 342 & 33.9 & & & & \\
\hline Unemployed & 719 & 35.6 & 389 & 38.6 & 342 & 34.1 & 263 & 26.3 & 327 & 32.5 & & & & \\
\hline Political views & & & & & & & & & & & & & & \\
\hline Liberal & 666 & 33 & 304 & 30.2 & 362 & 36.1 & 307 & 30.7 & 287 & 28.5 & $<.0001$ & $<.0001$ & 0.041 & $<.0001$ \\
\hline Moderate & 592 & 29.3 & 355 & 35.2 & 346 & 34.5 & 344 & 34.4 & 408 & 40.5 & & & & \\
\hline Conservative & 579 & 28.6 & 176 & 17.4 & 131 & 13 & 225 & 22.5 & 158 & 15.7 & & & & \\
\hline Don't know/ prefer not to answer & 183 & 9.1 & 173 & 17.2 & 163 & 16.3 & 125 & 12.5 & 154 & 15.2 & & & & \\
\hline COVID -19 & & & & & & & & & & & & & & \\
\hline Positive test-self & 220 & 10.9 & 179 & 17.8 & 102 & 10.1 & 158 & 15.8 & 89 & 8.8 & 0.068 & 0.532 & 0.071 & 0.416 \\
\hline Positive test-household member & 219 & 10.9 & 90 & 9 & 145 & 14.5 & 135 & 13.5 & 85 & 8.4 & & & & \\
\hline Both & 60 & 3 & 31 & 3.1 & 46 & 4.6 & 46 & 4.6 & 43 & 4.3 & & & & \\
\hline Negative test or not tested & 1520 & 75.3 & 707 & 70.2 & 708 & 70.7 & 662 & 66.1 & 790 & 78.4 & & & & \\
\hline Geographic location & & & & & & & & & & & & & & \\
\hline Rural & 334 & 16.5 & 5 & 0.5 & 0 & 0 & 66 & 6.6 & 11 & 1.1 & $\mathrm{n} / \mathrm{a}$ & $\mathrm{n} / \mathrm{a}$ & $\mathrm{n} / \mathrm{a}$ & $\mathrm{n} / \mathrm{a}$ \\
\hline Non-Rural & 1686 & 83.5 & 1002 & 99.5 & 1001 & 100 & 936 & 93.4 & 996 & 98.9 & & & & \\
\hline Vaccine received ( 1 dose or 2 doses) & 658 & 32.6 & 398 & 39.5 & 367 & 36.7 & 344 & 34.4 & 412 & 40.9 & $<.0001$ & $<.0001$ & 0.526 & $<.0001$ \\
\hline Vaccine not received but planned & 929 & 46 & 508 & 50.4 & 519 & 51.8 & 460 & 45.9 & 483 & 47.9 & & & & \\
\hline Vaccine not received and not planned & 433 & 21.4 & 101 & 10.1 & 115 & 11.5 & 197 & 19.7 & 112 & 11.2 & & & & \\
\hline
\end{tabular}

Table 1. Demographics and COVID-19 vaccine intention or uptake in each of the five samples. $n, \%$ are weighted to the geographic population; $P$-values are based on weighted chi-squared tests comparing each metropolitan areas to the national average. 


\begin{tabular}{|c|c|c|c|c|c|}
\hline & \multirow[b]{2}{*}{ National } & \multicolumn{4}{|c|}{ Metropolitan area } \\
\hline & & NY & LA & Dallas & Chicago \\
\hline & $\%$ & $\%$ & $\%$ & $\%$ & $\%$ \\
\hline \multicolumn{6}{|l|}{ Among vaccinated respondents } \\
\hline \multicolumn{6}{|l|}{ Reasons to receive vaccine } \\
\hline I want to protect myself from COVID-19 & 42.3 & 45.5 & 38.5 & 36.2 & 50 \\
\hline I want to protect my friends and family from COVID-19 & 30 & 28.5 & 26.2 & 33.5 & 24.4 \\
\hline To help end the pandemic more quickly & 23.4 & 21.3 & 25.2 & 25.5 & 19.7 \\
\hline I need it to get back to work & 2 & 2.9 & 2.3 & 2.3 & 3.6 \\
\hline My doctor or health plan/insurance recommended it & 2 & 1.4 & 7.8 & 2.2 & 2.2 \\
\hline \multicolumn{6}{|l|}{ Difficulty in making an appointment to get the vaccine } \\
\hline Yes & 36.2 & 43 & 30.3 & 36.6 & 42.8 \\
\hline \multicolumn{6}{|l|}{ Reasons for difficulty } \\
\hline I didn't know how to sign up for an appointment & 23.5 & 32.4 & 36 & 31.8 & 23.8 \\
\hline I didn't know if I was eligible for a vaccine & 19.5 & 13.8 & 18.5 & 18.2 & 17.3 \\
\hline There were no vaccination sites close to me & 30.5 & 44.9 & 30.8 & 30.2 & 36.4 \\
\hline I was worried about the cost & 17.5 & 4.3 & 5.7 & 8.4 & 17.7 \\
\hline Other & 5.8 & 4.5 & 8.9 & 11.4 & 4.9 \\
\hline \multicolumn{6}{|l|}{ Among respondents not yet vaccinated } \\
\hline \multicolumn{6}{|l|}{ Top reason for waiting } \\
\hline See how it works in other people & 23.8 & 22.3 & 15.6 & 19.9 & 19.2 \\
\hline Let high-risk people go first & 8.4 & 9.6 & 11.5 & 9.6 & 12.5 \\
\hline Wait until it is more convenient & 9.3 & 2.9 & 8.9 & 3.6 & 1.9 \\
\hline Wait until I know there are no serious complications & 58.5 & 65.2 & 64 & 66.9 & 66.4 \\
\hline \multicolumn{6}{|l|}{ What would help get ready for vaccine } \\
\hline Nothing will change my mind & 53.5 & 49.3 & 62.8 & 63.9 & 59.1 \\
\hline Assurance by a family member or close friend who got vaccinated & 12.8 & 2 & 6 & 6.4 & 1.2 \\
\hline Advice from community/religious leaders & 1.1 & 1.3 & 0.8 & 3.9 & 1.4 \\
\hline Recommendation from my family doctor & 9 & 15.2 & 6.3 & 5.4 & 4.6 \\
\hline Endorsement from a trusted political leader & 2.7 & & 0.4 & 1.9 & 3.8 \\
\hline Something else & 20.8 & 32.3 & 23.7 & 18.5 & 29.8 \\
\hline \multicolumn{6}{|l|}{ What would be the reason to receive vaccine } \\
\hline I want to protect myself from COVID-19 & 16.3 & 12.1 & 9.7 & 17 & 7.3 \\
\hline I want to protect my friends and family from COVID-19 & 14.3 & 32.5 & 18.9 & 10.1 & 8.1 \\
\hline To help end the pandemic more quickly & 11.1 & 6.7 & 9.6 & 9.2 & 14.9 \\
\hline I need it to get back to work & 5.4 & 5.5 & 0.9 & 7.2 & 7 \\
\hline My doctor or health plan/insurance recommended it & 5.1 & 5.3 & 3.9 & 2.2 & 10.6 \\
\hline I will not get the vaccine for any reason & 47.8 & 38 & 57.1 & 54.2 & 52.2 \\
\hline \multicolumn{6}{|l|}{ Where would you most prefer to get the vaccine? } \\
\hline Local pharmacy like CVS or Walgreens & 15.6 & 23.1 & 11.4 & 16.4 & 16 \\
\hline Hospital & 14.8 & 13.1 & 27.8 & 4.5 & 7.8 \\
\hline Sports stadium & 1 & 0.7 & 0.6 & 0.2 & 0.6 \\
\hline Your doctor's office & 38.5 & 39.1 & 36.2 & 44.7 & 50.9 \\
\hline Mobile unit send by the department of health to your neighborhood & 7.8 & 2.1 & 4.3 & 4.3 & 3 \\
\hline Local schools & 1.6 & 3.7 & 1.4 & 0 & 0.2 \\
\hline At a shopping mall or community centers & 0 & 1.6 & 0.4 & 0.5 & 0 \\
\hline My place of worship (e.g. church, temple, mosque) & 1.7 & 0.7 & 0.4 & 1.2 & 4.1 \\
\hline Somewhere else & 19 & 15.9 & 17.6 & 28.2 & 17.4 \\
\hline
\end{tabular}

Table 2. Vaccination reasons. \% are weighted to the geographic population.

Vaccination requirements and documentation. The majority of respondents agreed that employers have the right to require vaccination (Supplemental Table S4). Findings were even stronger with respect to universities requiring students to be vaccinated, but less so with respect to government-required vaccination.

Respondents overall expressed the highest level of approval for requiring proof of vaccination for international travel. However, approval for this policy was substantially lower among respondents who were unwilling to vaccinate or who reported conservative political views (Supplemental Figure S1). 


\begin{tabular}{|c|c|c|c|c|c|c|c|c|c|c|}
\hline & \multirow[b]{2}{*}{ National } & \multicolumn{9}{|c|}{ Metropolitan area } \\
\hline & & NY & LA & Dallas & Chicago & & NY & LA & Dallas & Chicago \\
\hline & $\%$ & $\%$ & $\%$ & $\%$ & $\%$ & $\begin{array}{l}\text { aOR }(95 \% \mathrm{CI}) \\
P \text {-value }\end{array}$ & $\begin{array}{l}\text { aOR }(95 \% \mathrm{CI}) \\
P \text {-value }\end{array}$ & $\begin{array}{l}\text { aOR }(95 \% \mathrm{CI}) \\
P \text {-value }\end{array}$ & $\begin{array}{l}\text { aOR }(95 \% \mathrm{CI}) \\
P \text {-value }\end{array}$ & $\begin{array}{l}\text { aOR }(95 \% \mathrm{CI}) \\
P \text {-value }\end{array}$ \\
\hline \begin{tabular}{|l|} 
Vaccine not \\
received and not \\
planned
\end{tabular} & 21.4 & 10.1 & 11.5 & 19.7 & 11.2 & - & - & - & - & - \\
\hline Age & & & & & & $<.0001$ & 0.218 & 0.002 & 0.001 & 0.043 \\
\hline $18-29$ & 24.2 & 10.5 & 14 & 24.5 & 13 & Ref & Ref & Ref & Ref & Ref \\
\hline $30-39$ & 22.3 & 18.2 & 12.2 & 24.1 & 10 & $1.03(0.59,1.78)$ & $1.41(0.44,4.54)$ & $0.83(0.16,4.23)$ & $1.20(0.41,3.49)$ & $1.47(0.26,8.31)$ \\
\hline $40-49$ & 29.4 & 11 & 10.6 & 22.7 & 12.6 & $1.18(0.64,2.16)$ & $0.66(0.15,2.87)$ & $0.49(0.11,2.07)$ & $0.64(0.22,1.92)$ & $2.42(0.43,13.55)$ \\
\hline $50-59$ & 25.2 & 8.9 & 14.6 & 16.1 & 13.9 & $0.76(0.40,1.42)$ & $1.03(0.25,4.23)$ & $0.58(0.17,2.05)$ & $0.49(0.17,1.40)$ & $0.86(0.15,5.09)$ \\
\hline $60-69$ & 17.5 & 6.6 & 11.4 & 11.4 & 8 & $0.38(0.18,0.80)$ & $0.58(0.16,2.12)$ & $0.16(0.04,0.71)$ & $0.16(0.05,0.54)$ & $0.37(0.05,2.68)$ \\
\hline $70+$ & 7.2 & 2.7 & 3.1 & 9.2 & 7.9 & $0.10(0.04,0.24)$ & $0.24(0.05,1.17)$ & $0.05(0.01,0.23)$ & $0.14(0.04,0.56)$ & $0.3(0.05,1.64)$ \\
\hline Sex & & & & & & 0.271 & 0.031 & 0.569 & 0.118 & 0.572 \\
\hline Male & 20.7 & 8.6 & 11.1 & 23.5 & 11.9 & Ref & Ref & Ref & Ref & ref \\
\hline Female & 21.6 & 11.5 & 11.9 & 16.4 & 8.5 & $1.24(0.85,1.82)$ & $2.41(1.08,5.36)$ & $1.29(0.54,3.07)$ & $0.60(0.31,1.14)$ & $1.34(0.49,3.71)$ \\
\hline Race & & & & & & 0.530 & 0.089 & 0.323 & 0.006 & 0.586 \\
\hline White & 22.6 & 12.8 & 15.8 & 27.7 & 10 & Ref & Ref & Ref & Ref & ref \\
\hline Black & 20.1 & 7.5 & 5.4 & 21.1 & 12 & $0.90(0.52,1.57)$ & $0.61(0.19,2.03)$ & $0.40(0.08,2.15)$ & $1.10(0.45,2.73)$ & $1.6(0.44,5.81)$ \\
\hline Latino/a & 19.3 & 9.5 & 8.2 & 8.3 & 9.9 & $0.64(0.34,1.22)$ & $0.37(0.09,1.45)$ & $0.51(0.18,1.46)$ & $0.20(0.07,0.57$ & $2.29(0.62,8.47)$ \\
\hline Asian & 17.6 & 1.6 & 11.7 & 4.7 & 9.6 & $0.72(0.28,1.88)$ & $0.13(0.02,0.80)$ & $0.41(0.12,1.38$ & $0.08(0.01,0.81)$ & $0.65(0.1,4.36)$ \\
\hline \begin{tabular}{|l|}
$\begin{array}{l}\text { Highest level of } \\
\text { education }\end{array}$ \\
\end{tabular} & & & & & & 0.227 & 0.042 & 0.033 & $<.001$ & 0.017 \\
\hline $\begin{array}{l}\begin{array}{l}\text { High school degree } \\
\text { or less }\end{array} \\
\end{array}$ & 24.8 & 8.7 & 7.8 & 24.3 & 9.5 & Ref & Ref & Ref & Ref & Ref \\
\hline Some college & 23.7 & 14 & 18.3 & 22.4 & 12.9 & $0.93(0.58,1.50)$ & $2.42(0.75,7.83)$ & $1.83(0.59,5.62)$ & $0.92(0.36,2.36)$ & $1.67(0.51,5.50)$ \\
\hline Bachelor's Degree & 16.3 & 12.3 & 12.6 & 13.7 & 16 & $0.66(0.42,1.02)$ & $1.53(0.47,5.04)$ & $0.81(0.22,2.97)$ & $0.28(0.11,0.74)$ & $3.12(0.93,10.44)$ \\
\hline $\begin{array}{l}\text { Graduate degree or } \\
\text { more }\end{array}$ & 14.6 & 5.3 & 6.4 & 11.9 & 4.7 & $0.80(0.47,1.35)$ & $0.49(0.13,1.85)$ & $0.30(0.06,1.36)$ & $0.18(0.06,0.57)$ & $0.32(0.05,1.96)$ \\
\hline Household income & & & & & & $<.0001$ & 0.060 & 0.088 & 0.102 & 0.611 \\
\hline$<\$ 25,000$ & 35.1 & 13.9 & 20.4 & 32.8 & 6.8 & ref & ref & ref & Ref & Ref \\
\hline$\$ 25,000-\$ 74,999$ & 21.5 & 8.4 & 6.6 & 13.3 & 9.8 & $0.41(0.23,0.72)$ & $0.20(0.05,0.8)$ & $0.13(0.03,0.57)$ & $0.43(0.12,1.57)$ & $0.91(0.17,4.85)$ \\
\hline$\$ 75,000-\$ 150,000$ & 15.8 & 11 & 11.8 & 17.3 & 13.5 & $0.2(0.16,0.52)$ & $0.37(0.1,1.33)$ & $0.3(0.07,1.28)$ & $0.55(0.14,2.08)$ & $2.43(0.38,15.56)$ \\
\hline$>\$ 150,000$ & 14.2 & 6.6 & 12.5 & 21.2 & 12.7 & $0.20(0.10,0.42)$ & $0.14(0.02,0.95)$ & $0.44(0.09,2.17)$ & $1.06(0.26,4.30)$ & $1.61(0.23,11.48)$ \\
\hline Prefer not to say & 19.4 & 11.1 & 14.3 & 30.5 & 11.4 & $0.26(0.10,0.64)$ & $0.08(0.01,0.58)$ & $0.44(0.09,2.16)$ & $1.96(0.47,8.20)$ & $0.80(0.09,7.17)$ \\
\hline Employment & & & & & & 0.007 & 0.081 & 0.632 & $<.001$ & 0.854 \\
\hline Working from home & 16.3 & 9.4 & 13.1 & 9 & 8.6 & $0.47(0.27,0.82)$ & $3.44(0.96,12.39)$ & $1.09(0.32,3.69)$ & $0.59(0.21,1.62)$ & $0.99(0.31,3.12)$ \\
\hline $\begin{array}{l}\text { Working outside the } \\
\text { home }\end{array}$ & 29 & 15.7 & 11.3 & 27.3 & 16.9 & $0.90(0.53,1.52)$ & $3.47(1.15,10.50)$ & $1.79(0.43,7.41)$ & $3.02(1.17,7.80)$ & $0.70(0.17,2.85)$ \\
\hline Unemployed & 20.8 & 6.4 & 10.3 & 21.1 & 7.7 & Ref & Ref & Ref & Ref & Ref \\
\hline \begin{tabular}{|l|} 
Political views \\
\end{tabular} & & & & & & $<.0001$ & $<.0001$ & $<.001$ & $<.0001$ & $<.0001$ \\
\hline \begin{tabular}{|l|} 
Liberal \\
\end{tabular} & 10.9 & 3.6 & 7.1 & 15.3 & 1.9 & Ref & Ref & Ref & & \\
\hline Moderate & 25.5 & 8.2 & 9.5 & 7.8 & 8.5 & $3.96(2.34,6.70)$ & $3.01(1.22,7.47)$ & $2.11(0.73,6.09)$ & & \\
\hline Conservative & 26.7 & 19.3 & 24.6 & 37.9 & 22 & $5.42(3.18,9.21)$ & $8.30(2.98,23.17)$ & $9.12(3.04,27.37)$ & & \\
\hline $\begin{array}{l}\text { Don't know/ prefer } \\
\text { not to answer }\end{array}$ & 29.9 & 15.8 & 14.9 & 30.4 & 24.3 & $4.88(2.22,10.76)$ & - & - & & \\
\hline COVID-19 & & & & & & 0.001 & 0.099 & 0.001 & 0.446 & 0.138 \\
\hline Positive test-self & 9.4 & 9.8 & 0.6 & 8.4 & 12.9 & $0.33(0.16,0.67)$ & $0.29(0.08,1.00)$ & $0.03(0.00,0.27)$ & & \\
\hline \begin{tabular}{|l|}
$\begin{array}{l}\text { Positive test- house- } \\
\text { hold member }\end{array}$ \\
\end{tabular} & 17.0 & 7.1 & 4.4 & 21.7 & 4.7 & $0.54(0.29,1.02)$ & $0.34(0.05,2.13$ & $0.09(0.01,0.57)$ & & \\
\hline Both & 12.3 & 1.9 & 6.0 & 19.3 & 23.8 & $0.25(0.08,0.74)$ & $0.09(0.01,1.33)$ & $0.61(0.10,3.93)$ & & \\
\hline $\begin{array}{l}\text { Negative test or not } \\
\text { tested }\end{array}$ & 24.2 & 1.9 & 14.9 & 22.0 & 11.0 & Ref & Ref & Ref & & \\
\hline \multicolumn{11}{|l|}{ Geographic location } \\
\hline Rural & 79.1 & - & & & & - & - & - & - & \\
\hline \begin{tabular}{|l|} 
Non-rural \\
\end{tabular} & 78.5 & - & & & & - & - & - & - & \\
\hline
\end{tabular}

Table 3. Unwillingness to vaccinate by sociodemographic factors. $\%$ are weighted to the geographic population; $P$-value is for Type 3 test of overall effects based on weighted logistic regression (outcome $=$ unwillingness to vaccinate). In the Chicago metropolitan area model reference category for political view was changed to moderate due to small sample size in the liberal category. $a O R$ adjusted odds ratios, $C I$ confidence intervals. 


\begin{tabular}{|c|c|c|c|c|c|c|c|c|c|c|}
\hline & \multirow{2}{*}{\multicolumn{2}{|c|}{ National }} & \multicolumn{8}{|c|}{ Metropolitan areas } \\
\hline & & & \multicolumn{2}{|l|}{ NY } & \multicolumn{2}{|l|}{ LA } & \multicolumn{2}{|l|}{ Dallas } & \multicolumn{2}{|l|}{ Chicago } \\
\hline & M & SD & $\mathbf{M}$ & SD & M & SD & M & SD & M & SD \\
\hline $\begin{array}{l}\text { COVID-19 vaccine acceptance scale } \\
\text { (COVID-VAC) }\end{array}$ & 4.08 & 0.91 & 4.30 & 0.76 & 4.21 & 0.83 & 4.06 & 0.97 & 4.23 & 0.85 \\
\hline Vaccine received & 4.44 & 0.57 & 4.46 & 0.56 & 4.34 & 0.74 & 4.45 & 0.56 & 4.49 & 0.55 \\
\hline Vaccine not received but planned & 4.36 & 0.60 & 4.45 & 0.54 & 4.42 & 0.53 & 4.36 & 0.56 & 4.40 & 0.57 \\
\hline \multirow[t]{3}{*}{ Vaccine not received and not planned } & 2.91 & 0.92 & 2.95 & 0.98 & 2.87 & 0.98 & 2.66 & 1.04 & 2.57 & 0.89 \\
\hline & \multicolumn{2}{|l|}{ OR 95\%CI } & \multicolumn{2}{|l|}{ OR $95 \% \mathrm{CI}$} & \multicolumn{2}{|l|}{ OR 95\%CI } & \multicolumn{2}{|l|}{ OR 95\%CI } & \multicolumn{2}{|l|}{ OR 95\%CI } \\
\hline & $\mathbf{n}$ & $\%$ & $\mathbf{n}$ & $\%$ & $\mathbf{n}$ & $\%$ & $\mathbf{n}$ & $\%$ & $\mathbf{n}$ & $\%$ \\
\hline $\begin{array}{l}\text { COVID -VAC as a predictor of unwill- } \\
\text { ingness to vaccinate }\end{array}$ & \multicolumn{2}{|l|}{$10.16(7.01,14.71)$} & \multicolumn{2}{|l|}{$9.59(5.33,17.25)$} & \multicolumn{2}{|l|}{$6.43(3.13,13.23)$} & \multicolumn{2}{|l|}{$12.18(7.75,19.16)$} & \multicolumn{2}{|l|}{$14.17(6.65,30.20)$} \\
\hline \multicolumn{11}{|l|}{ COVID-19 is a dangerous health threat } \\
\hline Strongly agree/agree & 1697 & 84 & 910 & 90.4 & 829 & 82.8 & 824 & 82.3 & 869 & 86.2 \\
\hline Unsure/disagree/strongly disagree & 323 & 16 & 97 & 9.6 & 172 & 17.2 & 178 & 17.7 & 138 & 13.8 \\
\hline \multicolumn{11}{|c|}{ COVID-19 can be prevented by vaccination } \\
\hline Strongly agree/agree & 1581 & 78.3 & 850 & 84.4 & 824 & 82.3 & 80.7 & 80.7 & 83.6 & 83.6 \\
\hline Unsure/disagree/strongly disagree & 439 & 21.7 & 157 & 15.6 & 177 & 17.7 & 19.3 & 19.3 & 16.4 & 16.4 \\
\hline \multicolumn{11}{|c|}{ The risks of COVID-19 disease are greater than the risks of the vaccine } \\
\hline Strongly agree/Agree & 1499 & 74.2 & 822 & 81.7 & 799 & 79.8 & 754 & 75.3 & 798 & 79.3 \\
\hline Unsure/Disagree/strongly disagree & 521 & 25.8 & 185 & 18.3 & 202 & 20.2 & 248 & 24.7 & 209 & 20.7 \\
\hline \multicolumn{11}{|c|}{ The COVID-19 vaccines available to me are safe } \\
\hline Strongly agree/agree & 1506 & 74.5 & 830 & 82.4 & 843 & 84.2 & 745 & 74.3 & 785 & 77.9 \\
\hline Unsure/disagree/strongly disagree & 514 & 25.5 & 177 & 17.6 & 158 & 15.8 & 257 & 25.7 & 222 & 22.1 \\
\hline \multicolumn{11}{|c|}{ I trust that my government is able to deliver the COVID-19 vaccine to everyone, everywhere in my country, equally } \\
\hline Strongly agree/agree & 1406 & 69.6 & 755 & 74.9 & 762 & 76.2 & 722 & 72.1 & 707 & 70.2 \\
\hline Unsure/disagree/strongly disagree & 614 & 30.4 & 252 & 25.1 & 239 & 23.8 & 280 & 27.9 & 300 & 29.8 \\
\hline \multicolumn{11}{|c|}{ I trust the science behind the COVID-19 vaccines } \\
\hline Strongly agree/agree & 1473 & 72.9 & 858 & 85.2 & 788 & 78.8 & 728 & 72.7 & 820 & 81.4 \\
\hline Unsure/disagree/strongly disagree & 547 & 27.1 & 149 & 14.8 & 213 & 21.2 & 274 & 27.3 & 187 & 18.6 \\
\hline
\end{tabular}

Table 4. COVID-VAC score and score components. \% are weighted to the geographic population; COVID -VAC as a predictor of unwillingness to vaccinate was evaluated using weighted logistic regression (outcome $=$ unwillingness to vaccinate). Original response options ranged from strongly agree $=1$ to strongly disagree $=5$ for the presented item. OR odds ratios, $C I$ confidence intervals.

Preferred vaccination locations among those not vaccinated. Amongst currently unvaccinated respondents, the doctor's office was the preferred choice for receiving the vaccine. The local pharmacy was a distant second (Table 2).

Sources of vaccine information. There was a high level of agreement that the CDC is the leading source of information about COVID-19 vaccination (Supplemental Table S5), followed at some distance by local health providers. The respondents' preferred media for obtaining COVID-19 information were cable TV and local news. This finding was consistent across racial and ethnic groups (Data not shown in table).

Top priorities and rationales for vaccination. Among respondents who were vaccinated or planned to do so, the top priority was "getting everyone vaccinated as soon as possible" (Supplemental Table S5), followed by "getting children back to school" and "getting people back to work". Among the minority of respondents who said they were unwilling to vaccinate, the top priority for them to even consider doing so was "getting people back to work".

\section{Discussion}

This study on COVID-19 vaccine acceptance in the United States found sharp contrasts in vaccination willingness among unvaccinated respondents in the national sample compared to the four metropolitan areas studied. Unwillingness to vaccinate was not uniformly distributed by age or racial group in any of the five populations surveyed. Those expressing COVID-19 vaccine hesitancy were unlikely to change their mind, most likely to have less education and lower income, and to work outside of the home. Respondents who reported that they or another household member had tested positive for COVID-19 were strongly motivated to accept vaccination.

Recent studies report levels of COVID-19 vaccine hesitancy in the United States ranging from $22 \%$ to $42.4 \%{ }^{14,28,31,32}$, similar to the range we report. One study reported even lower vaccination intent in the New York and Chicago regions for the Department of Health and Human Services ${ }^{13}$. Our finding that half of those 
respondents who expressed unwillingness to vaccinate said that "nothing would change their minds," should be a serious concern. Reassurance from family members or recommendations from doctors were reported "unlikely" to change this opinion, a level of recalcitrance that must be addressed in future policies and interventions.

It is important to consider key factors that differentiate those who are vaccine hesitant compared to those who are adamantly opposed to vaccination. The literature on COVID-19 vaccine hesitancy identifies lower education, income, and age; low perceived threat of infection; racial differences (Black or Latino/a vs White or Asian); political affiliation; living in a rural or generally remote area; and low trust in government, health authorities and scientific sources as key associations ${ }^{14,28,31,32}$. COVID-19 vaccine-specific concerns, assessed in COVID-VAC below, suggest a higher perceived risk of complications from the vaccines ${ }^{13,32}$. This risk perception is further amplified by the relatively lower conviction of dangers of COVID-19 disease among the sub-cohort of vaccine resisters.

Poverty was most frequently associated with unwillingness to vaccinate, with the exception of the Chicago metropolitan area. Hesitancy was also high among those who work outside the home, some of whom continued to perform essential but low-wage work even after lockdown ${ }^{33,34}$. In the Dallas metropolitan area, unemployment was also associated with unwillingness to vaccination. Limited economic resources are associated with conflicting life priorities that prevent individuals from prioritizing vaccination. Workers outside the home who have not yet been infected may have developed a perception of low risk from COVID-19 14,17,35,36.

Many sources cite lower average vaccine acceptance among Blacks compared to other racial and ethnic groups ${ }^{22,37-39}$. Recent polls, including this study, indicate a relative increase in COVID-19 vaccine acceptance among Black respondents, however ${ }^{40}$. Our results found no consistent racial patterns to vaccine hesitancy. In the NY and LA metropolitan areas, white respondents were more likely than Black respondents to express COVID19 vaccine unwillingness. The reverse was true in the Chicago and Dallas metropolitan areas. These findings caution against demographic generalizations regarding vaccine acceptance, and emphasize the importance of assessing local context when tailoring interventions and messaging. Stereotyping racial attitudes could even lead to disenfranchisement of communities of color that are increasingly well-motivated to participate in vaccination $\operatorname{programs}^{37,41,42}$.

The primary motivators to get vaccinated were "protecting myself against COVID-19", followed by "protecting my family and friends"; these elements should remain at the core of vaccine communications messages. Testing positive for COVID-19 was a particularly strong motivator of vaccine acceptance. Continuing to encourage testing will counter misconceptions that the spread of the pandemic is over. As people continue to test positive across age, race, and ideology, this may encourage them to accept vaccination as a necessary protection.

The four metropolitan areas were chosen to cover all four US geographical regions with a significant combined proportion of the US population, their combined numbers of COVID-19 cases as a percentage of the US total, and their disproportionate influence on the national economy, cultural and informational trends ${ }^{43,44}$. Their high population density, greater reliance on public transport and status as major hubs of vacation and business travel also put them at particular risk for pandemic spread. Residents of these metropolitan areas have higher educational attainment and median income than national averages, but share equal or higher levels of poverty and unemployment; their racial and ethnic mix tends to favor higher representation of people of color (Supplemental Table S1) $)^{37,45,46}$.

Greater acceptance of vaccination may be higher in the New York, Chicago and Los Angeles metropolitan areas due to the more liberal political leanings of their residents. The politicization of the COVID-19 vaccine and other response efforts is well documented in the United States ${ }^{77,48}$. Conservative political affiliation is strongly associated with COVID-19 vaccine hesitancy ${ }^{18,49}$ as well as for other prevention measures such as facemask use, physical distancing, and stay-at-home orders ${ }^{50}$. When evaluating a decision to vaccinate, US conservatives may undervalue the risk to physical health posed by COVID-19 in relation to other perceived risks ${ }^{7,51}$, such as violation of individual autonomy or misconceptions of risks posed by vaccination ${ }^{52,53}$. In our study, holding conservative political views was associated with higher hesitancy across all metropolitan areas, whereas in the national sample moderate and conservative respondents were almost equally unwilling to accept a vaccine. Conservative respondents were more likely to believe falsely that vaccination would not prevent COVID-19 (with the exception of the LA metropolitan area).

Effective motivation of those holding conservative views should link vaccine coverage with returning to work, the top priority expressed by respondents with conservative views. Support from vaccine advocates and media channels with conservative views may mitigate hesitancy among this audiences ${ }^{54}$.

COVID-VAC showed external and internal validity, and predicted (from six times as often in LA to ten times as often nationally) the likelihood of vaccine acceptance. Agreement that COVID-19 is a dangerous health threat was high nationally and in the four metropolitan areas, even among those unwilling to vaccinate; in contrast, trust in the government's ability to distribute vaccines fairly was uniformly lower for all respondents. This scale can be used to predict vaccination behaviors and as a comparative tool.

General and COVID-19-specific mistrust in the government and concerns about vaccine safety and efficacy are commonly cited as drivers of vaccine hesitance ${ }^{6,38,55,56}$. Trust in government regulation of vaccine development has significant influence on public confidence in vaccine safety and efficacy ${ }^{57}$. However, although trust in public health authorities is often cited as a source of confidence, it may not always play a significant role in the decisions of some Black people to accept a COVID-19 vaccine ${ }^{58}$.

Respondents from all study settings were more likely to support required proof of vaccination for access to international travel than domestic indoor events. Respondents were also more likely to accept employer vaccination mandates than government ones. As expected, those holding conservative poltical views were least likely to accept employer mandates and even less so a government one ${ }^{59}$. Though each state has the authority, none currently requires adult immunization against any disease ${ }^{60}$, and only a few are considering COVID-19 vaccination mandates ${ }^{61}$. 
Although states require routine childhood immunization ${ }^{62}$, a pattern of increased vaccine hesitancy has been observed over the past decade ${ }^{63}$. Colleges and universities typically require state-mandated childhood vaccines and often require additional vaccines, such as hepatitis $A$ and meningitis $B^{64}$. A relatively high number of respondents in this study agreed that university students should be required to take the COVID-19 vaccine, a finding that has not yet been explored in COVID-19 literature.

In a CDC survey conducted in May 2020, public support for stay-at-home orders and closure of non-essential businesses was higher in NY (86.7\%) and Los Angeles, CA (81.5\%) than the national average (79.5\%), with similar proportions reporting that state restrictions were not too restrictive ${ }^{65}$. Our results indicate a similar high level of support for vaccination requirements in these metropolitan areas, suggesting that risk communication strategies emphasizing individual empowerment and civic responsibility may be effective ${ }^{66,67}$.

All respondents tended to choose the CDC as their preferred source of vaccine information. Vaccine hesitant respondents were also likely to select other options, such as community leaders and local and state governments, suggesting that deploying community and local political leaders could be an appropriate strategy to reach them ${ }^{68,69}$.

In our study, the preferred media for respondents to obtain vaccine information were the internet and social media, followed by cable and local news. Both preferences can be double-edged swords. The internet and social media are sources of misinformation and disinformation, most commonly promulgated by political conservatives, including anti-vaccine activists ${ }^{70,71}$. Cable and online news organizations often supplant sensational crises or political content ${ }^{72}$. For example, viewers of one cable news provider were persuaded to not comply with social distancing recommendations ${ }^{73}$. Those who are hesitant may be more receptive, not only to online claims of misinformation, but to sensationalised reports on adverse effects and vaccine risks. Trusted sources should take proactive roles in delivering balanced, accurate information in internet, social, cable news and local TV media.

Most respondents preferred to receive COVID-19 vaccination in their doctors' offices, fewer at local pharmacies or hospitals. Very few chose sports arenas, places of worship or mobile units. Opportunities for vaccination may be missed with routine health visits when the doctor's office is ill-equipped to vaccinate ${ }^{74}$. As the first wave of enthusiasts is vaccinated, there will be a substantial decline in demand for vaccinations outside the routine healthcare setting ${ }^{75}$. Moving forward, ensuring proper storage and administration capability at primary healthcare facilities may be the way to accommodate public preferences ${ }^{76,77}$.

This study provides an in-depth understanding of perceptions underlying COVID-19 vaccine acceptance in the US, and describes motivational factors that could be used to sway those who are unsure or opposed to vaccination. Lower income and conservative ideology were strongly associated with vaccine hesitancy, as well as mistrust in vaccine efficacy and safety and underestimation of the risk of COVID-19. Non-immunization among these populations may delay or prevent reaching the level of herd immunity required to end this pandemic. Effective, targeted interventions are needed urgently. The COVID-VAC tool could be applied to specific populations, for example vaccine hesitant and vulnerable groups, to inform and further refine policies and strategies domestically and globally.

\section{Methods}

Sampling frame. A sampling frame of 242,127,140 US residents 18 years and older was employed. More than $80 \%$ of the US population live in urban areas ${ }^{78}$ and in 2019 the four largest metropolitan statistical areas had an estimated total population of approximately 50.5 million, representing approximately $15 \%$ of the total US population ${ }^{79}$. Five stratified proportionate randomized population based samples were drawn, one for each of the four most populous metropolitan statistical areas in the US: Northeast (New York-Newark-Jersey City, New York-New Jersey-Pennsylvania), Midwest (Chicago-Naperville-Elgin, Illinois-Indiana-Wisconsin), West (Los Angeles-Long Beach-Anaheim, California) and South (Dallas-Fort Worth-Arlington, Texas), and a fifth nationwide sample covering urban, semi-urban and rural geographies.

Survey instrument design. A 36-item instrument (Supplemental File S1) was created by an expert panel following a comprehensive literature review of COVID-19 vaccine acceptance studies ${ }^{28}$. The instrument included a 6-item COVID-VAC scale representing perceptions of risk, trust, safety, and efficacy. The domains were adapted from vaccine acceptance predictors identified in earlier general vaccine confidence studies ${ }^{6,80-89}$.

Multi-mode data collection design. Personalized short message service (SMS) text messages sent to each respondent. included a link to the survey and an opt-out option. Respondents could reply to the text with any queries and live operators were available to follow up with participants, also via SMS.

Interactive voice response (IVR) aka robo-poll messages were sent to landlines using a voice recorded IVR platform. An online opt-in panel of respondents was provided by Consensus Strategies and utilized to offset deficiency in the sample design with younger participants. The platforms were available in English and Spanish. Data were collected April 10-14, 2021.

Data analysis. Demographic weights, developed based on the 2019 American Community Survey singleyear estimates ${ }^{90}$, were applied: self-identified gender (male, female, prefer not to say and "other" categories), age (18-29, 30-39, 40-49, 50-59, 60-69, 70+); race and ethnicity (African American/Black, Asian, Caucasian/ White, American Indian, Native Hawaiian, Hispanic, and multiple/other); education (High School or less, some college, college degree, post graduate); census regions were used for the four metropolitan statistical areas and the Northeast, South, Midwest and West census regions were used for the national study.

The study reports COVID-19 vaccine acceptance among the following self-reporting sub-groups: (1) already vaccinated; (2) unvaccinated but willing to accept a vaccine; and (3) unvaccinated and unwilling to vaccinate. 
Trends were analysed using weighted descriptive statistics and chi-squared tests in the four metropolitan areas compared to the national averages. Associations between unwillingness to vaccinate and sociodemographic and political factors were assessed using weighted logistic regressions.

The paper also examined the predictive value of COVID-VAC, a novel scale that averages the reversed scores for survey items $1-6$, based on responses ranging from strongly agree $=1$ to strongly disagree $=5$. Dimensionality of the scale was assessed using a principal component analysis (PCA) and reliability using Cronbach's alpha. Weighted logistic regressions were used to evaluate its predictive capacity of perceptions most associated with vaccine acceptance. Statistical analyses were conducted using SAS version 9.4. Statistical significance was set at $\alpha=0.05$.

Ethics statement. This study was approved by the Emerson College Institutional Review Board (protocol number 20-023-F-E6/12), original expiration date of 11 June 2021. A renewal request was accepted on 12 April 2021 to extend the expiration date to 11 June 2022. The online questionnaire was administered after obtaining respondents' informed consent on the landing page, which contained information about the survey and the purpose of this project. To comply with ethical compensation standards, equitable compensation per survey was applied (approximately US\$2 per completion). Respondents' identities were verified using IP addresses or mobile phones to ensure that each participant was real and unique upon initial registration, though this data, nor any other personally-identifiable data, were stored, as recommended by the British Psychological Society Ethics Guidelines for Internet-mediated Research and in adherence to the principles of the Declaration of Helsinki.

Received: 10 June 2021; Accepted: 15 October 2021

Published online: 04 November 2021

\section{References}

1. Worldometer. COVID-19 Coronavirus Pandemic. https://doi.org/10.1101/2020.01.23.20018549V2

2. Our World in Data. Coronavirus (COVID-19) Vaccinations. Statistics and Research. https://ourworldindata.org/covid-vaccinatio ns. Published April 20, 2021. Accessed October 1, 2021.

3. Worldometer. United States Coronavirus. https://www.worldometers.info/coronavirus/country/us/. Published April 14, 2020. Accessed October 1, 2021.

4. US Centers for Disease Control and Prevention. COVID Data Tracker. https://covid.cdc.gov/covid-data-tracker/\#vaccinationtrends. Published April 14, 2021. Accessed October 1, 2021.

5. U.S. Census Bureau. United States Population Clock. https://www.census.gov/popclock/. Published April 13, 2021. Accessed October 1, 2021.

6. MacDonald, N. E. et al. Vaccine hesitancy: definition, scope and determinants. Vaccine. 33(34), 4161-4164. https://doi.org/10. 1016/j.vaccine.2015.04.036 (2015).

7. Peretti-Watel, P., Larson, H., Ward, J., Schulz, W. \& Verger, P. Vaccine hesitancy: clarifying a theoretical framework for an ambiguous notion. PLoS Curr. https://doi.org/10.1371/CURRENTS.OUTBREAKS.6844C80FF9F5B273F34C91F71B7FC289 (2015).

8. Sallam, M. COVID-19 vaccine hesitancy worldwide: a concise systematic review of vaccine acceptance rates. Vaccines $9(2)$, 160 . https://doi.org/10.3390/VACCINES9020160 (2021).

9. Suzanna, A. B. et al. Factors affecting COVID-19 vaccine acceptance: an international survey among low- and middle-income countries. Vaccines. https://doi.org/10.3390/VACCINES9050515 (2021).

10. Caserotti, M. et al. Associations of COVID-19 risk perception with vaccine hesitancy over time for Italian residents. Soc. Sci. Med. 272, 113688. https://doi.org/10.1016/J.SOCSCIMED.2021.113688 (2021).

11. MacDonald, N. E. SAGE working group on vaccine hesitancy. Vaccine hesitancy: definition, scope and determinants. Vaccine. 33(34), 4161-4164. https://doi.org/10.1016/j.vaccine.2015.04.036 (2015).

12. Karafillakis, E. \& Larson, H. J. ADVANCE consortium. The benefit of the doubt or doubts over benefits? A systematic literature review of perceived risks of vaccines in European populations. Vaccine. 35(37), 4840-4850. https://doi.org/10.1016/j.vaccine.2017. 07.061 (2017).

13. Malik, A. A., McFadden, S. A. M., Elharake, J. \& Omer, S. B. Determinants of COVID-19 vaccine acceptance in the US. EClinicalMedicine. 26, 100495. https://doi.org/10.1016/j.eclinm.2020.100495 (2020).

14. Khubchandani, J. et al. COVID-19 vaccination hesitancy in the United States: a rapid national assessment. J. Commun. Health. 46(2), 270-277. https://doi.org/10.1007/s10900-020-00958-x (2021).

15. Nguyen, K. H. et al. COVID-19 vaccination intent, perceptions, and reasons for not vaccinating among groups prioritized for early vaccination-United States, september and december 2020. Am. J. Transpl. 21(4), 1650-1656. https://doi.org/10.1111/ajt.16560 (2021).

16. Salmon, D. A. et al. COVID-19 vaccination attitudes, values and intentions among United States adults prior to emergency use authorization. Vaccine. https://doi.org/10.1016/j.vaccine.2021.03.034 (2021).

17. Latkin, C. A., Dayton, L., Yi, G., Konstantopoulos, A. \& Boodram, B. Trust in a COVID-19 vaccine in the U.S.: a social-ecological perspective. Soc. Sci. Med. 270, 113684. https://doi.org/10.1016/j.socscimed.2021.113684 (2021).

18. Weisel, O. Vaccination as a social contract: the case of COVID-19 and US political partisanship. Proc. Natl. Acad. Sci. 118(13), e2026745118. https://doi.org/10.1073/pnas.2026745118 (2021).

19. Ruiz, J. B. \& Bell, R. A. Predictors of intention to vaccinate against COVID-19: results of a nationwide survey. Vaccine. 39(7), 1080-1086. https://doi.org/10.1016/j.vaccine.2021.01.010 (2021).

20. Harrison, J., Berry, S., Mor, V. \& Gifford, D. "Somebody Like Me": understanding COVID-19 vaccine hesitancy among staff in skilled nursing facilities. J. Am. Med. Dir. Assoc. https://doi.org/10.1016/j.jamda.2021.03.012 (2021).

21. Nguyen, L. H. et al. Racial and ethnic differences in COVID-19 vaccine hesitancy and uptake. medRxiv. https://doi.org/10.1101/ 2021.02.25.21252402 (2021).

22. Nguyen, K. H. et al. COVID-19 vaccination intent, perceptions, and reasons for not vaccinating among groups prioritized for early vaccination-United states, september and december 2020. Am. J. Transpl. 21(4), 1650-1656. https://doi.org/10.1111/ajt.16560 (2021).

23. Guidry, J. P. D. et al. Willingness to get the COVID-19 vaccine with and without emergency use authorization. Am. J. Infect. Control. 49(2), 137-142. https://doi.org/10.1016/j.ajic.2020.11.018 (2021). 
24. Fridman, A., Gershon, R. \& Gneezy, A. COVID-19 and vaccine hesitancy: a longitudinal study Capraro V, ed. PLoS One. 16(4), 250123. https://doi.org/10.1371/journal.pone.0250123 (2021).

25. Skjefte, M. et al. COVID-19 vaccine acceptance among pregnant women and mothers of young children: results of a survey in 16 countries. Eur. J. Epidemiol. 36(2), 197-211. https://doi.org/10.1007/s10654-021-00728-6 (2021).

26. Szilagyi, P. G. et al. National trends in the US Public's likelihood of getting a COVID-19 vaccine-april 1 to december 8, 2020. JAMA 325(4), 396-398. https://doi.org/10.1001/jama.2020.26419 (2020).

27. Bokemper, S. E., Huber, G. A., Gerber, A. S., James, E. K. \& Omer, S. B. Timing of COVID-19 vaccine approval and endorsement by public figures. Vaccine. 39(5), 825-829. https://doi.org/10.1016/j.vaccine.2020.12.048 (2021).

28. Lazarus, J. V. et al. A global survey of potential acceptance of a COVID-19 vaccine. Nat. Med. 2, 51 (2021).

29. Lin, C., Tu, P. \& Beitsch, L. M. Confidence and receptivity for covid-19 vaccines: a rapid systematic review. Vaccines. 9(1), 1-32. https://doi.org/10.3390/vaccines9010016 (2021).

30. Hamel, L. \& Brodie, M. KFF COVID-19 Vaccine Monitor: What We've Learned. Kaiser Family Foundation. https://www.kff.org/ coronavirus-covid-19/poll-finding/kff-covid-19-vaccine-monitor-what-weve-learned-april-2021/ (2021). Accessed April 22, 2021.

31. Fisher, K. A. et al. Attitudes toward a potential SARS-CoV-2 vaccine: a survey of US Adults. Ann. Intern. Med. 173(12), 964-973. https://doi.org/10.7326/M20-3569 (2020).

32. Pogue, K. et al. Influences on attitudes regarding potential covid-19 vaccination in the United States. Vaccines. 8(4), 1-14. https:// doi.org/10.3390/vaccines8040582 (2020).

33. Jay, J. et al. Neighbourhood income and physical distancing during the COVID-19 pandemic in the United States. Nat. Hum. Behav. 4(12), 1294-1302. https://doi.org/10.1038/s41562-020-00998-2 (2020).

34. Dingel, J. I. \& Neiman, B. How many jobs can be done at home?. J. Public Econ. 189, 104235. https://doi.org/10.1016/j.jpubeco. 2020.104235 (2020).

35. Mercadante, A. R. \& Law, A. V. Will they, or Won't they? examining patients' vaccine intention for flu and COVID-19 using the health belief model. Res. Soc. Adm. Pharm. https://doi.org/10.1016/j.sapharm.2020.12.012 (2021).

36. Wagner, C. E. et al. Economic and behavioral influencers of vaccination and antimicrobial use. Front. Public. Heal. 8, 10. https:// doi.org/10.3389/fpubh.2020.614113 (2020)

37. Burger, A. E., Reither, E. N., Mamelund, S. E. \& Lim, S. Black-white disparities in 2009 H1N1 vaccination among adults in the United States: a cautionary tale for the COVID-19 pandemic. Vaccine. 39(6), 943-951. https://doi.org/10.1016/j.vaccine.2020.12. $069(2021)$.

38. Callaghan, T. et al. Correlates and disparities of COVID-19 vaccine hesitancy. SSRN Electron. J. https://doi.org/10.2139/ssrn.36679 $71(2020)$.

39. Latkin, C. et al. COVID-19 vaccine intentions in the United States, a social-ecological framework. Vaccine. 39(16), 2288-2294. https://doi.org/10.1016/j.vaccine.2021.02.058 (2021).

40. Hamel, L., Lopes, L., Kearney, A., \& Brodie, M. KFF COVID-19 Vaccine Monitor: March 2021. Kaiser Family Foundation. https:// www.kff.org/coronavirus-covid-19/poll-finding/kff-covid-19-vaccine-monitor-march-2021/ (2021). Accessed April 15, 2021.

41. Gover, A. R., Harper, S. B. \& Langton, L. Anti-Asian hate crime during the COVID-19 pandemic: exploring the reproduction of inequality. Am. J. Crim. Justice. 45(4), 647-667. https://doi.org/10.1007/s12103-020-09545-1 (2020).

42. Dunham, Y., Lieberman, E. S. \& Snell, S. A. Does stigmatized social risk lead to denialism? results from a survey experiment on race, risk perception, and health policy in the United States. Tayo BO, ed. PLoS One. 11(3), e0147219. https://doi.org/10.1371/ journal.pone.0147219 (2016)

43. Balland, P. A. et al. Complex economic activities concentrate in large cities. Nat. Hum. Behav. 4(3), 248-254. https://doi.org/10. 1038/s41562-019-0803-3 (2020).

44. Ottaviano, G. I. P. \& Peri, G. The economic value of cultural diversity: evidence from US cities. J. Econ. Geogr. 6(1), 9-44. https:// doi.org/10.1093/jeg/lbi002 (2006).

45. Freimuth, V. S., Jamison, A. M., An, J., Hancock, G. R. \& Quinn, S. C. Determinants of trust in the flu vaccine for African Americans and Whites. Soc. Sci. Med. 193, 70-79. https://doi.org/10.1016/j.socscimed.2017.10.001 (2017).

46. Quinn, S. C., Jamison, A. M., An, J., Hancock, G. R. \& Freimuth, V. S. Measuring vaccine hesitancy, confidence, trust and flu vaccine uptake: Results of a national survey of White and African American adults. Vaccine. 37(9), 1168-1173. https://doi.org/10. 1016/j.vaccine.2019.01.033 (2019).

47. Hart, P. S., Chinn, S. \& Soroka, S. Politicization and polarization in COVID-19 news coverage. Sci.. Commun. 42(5), 679-697. https://doi.org/10.1177/1075547020950735 (2020).

48. Gollust, S. E., Nagler, R. H. \& Fowler, E. F. The emergence of COVID-19 in the US: a public health and political communication crisis. J. Health Polit. Policy Law. https://doi.org/10.1215/03616878-8641506 (2020).

49. Hamel, L., Kirzinger, A., Muñana, C., \& Brodie, M. KFF COVID-19 vaccine monitor: december 2020. Kaiser Family Foundation. https://www.kff.org/coronavirus-covid-19/report/kff-covid-19-vaccine-monitor-december-2020/ (2020). Accessed April 15, 2021.

50. de Bruine, B. W., Saw, H. W. \& Goldman, D. P. Political polarization in US residents' COVID-19 risk perceptions, policy preferences, and protective behaviors. J. Risk Uncertain. 61(2), 177-194. https://doi.org/10.1007/s11166-020-09336-3 (2020).

51. Niepel, C., Kranz, D., Borgonovi, F., Emslander, V. \& Greiff, S. The coronavirus (COVID-19) fatality risk perception of US adult residents in March and April 2020. Br. J. Health Psychol. 25(4), 883-888. https://doi.org/10.1111/BJHP.12438 (2020).

52. Salmon, D. A. \& Omer, S. B. Individual freedoms versus collective responsibility: immunization decision-making in the face of occasionally competing values. Emerg. Themes Epidemiol. 3(1), 1-3. https://doi.org/10.1186/1742-7622-3-13 (2006).

53. Head, K. J., Kasting, M. L., Sturm, L. A., Hartsock, J. A. \& Zimet, G. D. A national survey assessing SARS-CoV-2 vaccination intentions: implications for future public health. Commun. Efforts 42(5), 698-723. https://doi.org/10.1177/1075547020960463 (2020).

54. Parks, M. A., Siegal, B., \& Selsky, L. How some Republican lawmakers are fighting conservatives' COVID-19 vaccine hesitancyABC News. ABC News. https://abcnews.go.com/Politics/republican-lawmakers-fighting-conservatives-covid-19-vaccine-hesit ancy/story?id=77169403 (2021). Accessed April 28, 2021.

55. Larson, H. J. et al. Measuring trust in vaccination: a systematic review. Hum. Vaccines Immunother. 14(7), 1599-1609. https://doi. org $/ 10.1080 / 21645515.2018 .1459252(2018)$

56. Quinn, S. C. et al. Exploring communication, trust in government, and vaccination intention later in the $2009 \mathrm{H} 1 \mathrm{~N} 1$ pandemic: Results of a national survey. Biosecur. Bioterror. 11(2), 96-106. https://doi.org/10.1089/bsp.2012.0048 (2013).

57. Badur, S., Ota, M., Öztürk, S., Adegbola, R. \& Dutta, A. Vaccine confidence: the keys to restoring trust. Hum. Vaccines Immunother. 16(5), 1007-1017. https://doi.org/10.1080/21645515.2020.1740559 (2020).

58. Woko, C., Siegel, L. \& Hornik, R. An investigation of low COVID-19 vaccination intentions among black Americans: the role of behavioral beliefs and trust in COVID-19 information sources. J. Health Commun. 25(10), 819-826. https://doi.org/10.1080/10810 $730.2020 .1864521(2020)$

59. McCoy, C. A. The social characteristics of Americans opposed to vaccination: beliefs about vaccine safety versus views of U.S. vaccination policy. Crit. Public Health. 30(1), 4-15. https://doi.org/10.1080/09581596.2018.1501467 (2020).

60. Gostin, L. O. \& Salmon, D. A. The dual epidemics of COVID-19 and influenza: vaccine acceptance, coverage, and mandates. JAMA J. Am. Med. Assoc. 324(4), 335-336. https://doi.org/10.1001/jama.2020.10802 (2020).

61. Association of Immunization Managers (AIM). Mandates: Bills \& Status. https://www.immunizationmanagers.org/general/custom. asp?page=IPP_Mandates_Bills-Status\&DGPCrSrt=\&DGPCrPg=1 (2021). Accessed April 19, 2021. 
62. National Conference of State Legislatures. State Immunization Policy Overview. https://www.ncsl.org/research/health/immunizati ons-policy-issues-overview.aspx (2021). Accessed April 28, 2021.

63. Bednarczyk, R. A., King, A. R., Lahijani, A. \& Omer, S. B. Current landscape of nonmedical vaccination exemptions in the United States: impact of policy changes. Expert. Rev. Vaccines. 18(2), 175-190. https://doi.org/10.1080/14760584.2019.1562344 (2019).

64. Fawole, O. A., Srivastava, T., Fasano, C. \& Feemster, K. A. Evaluating variability in immunization requirements and policy among U.S. Colleges and Universities. J. Adolesc. Heal. 63(3), 286-292. https://doi.org/10.1016/j.jadohealth.2018.06.013 (2018).

65. Czeisler, M. É. et al. Public attitudes, behaviors, and beliefs related to COVID-19, stay-at-home orders, nonessential business closures, and public health guidance-United States, New York City, and Los Angeles, May 5-12, 2020. MMWR Morb. Mortal Wkly. Rep. 69(24), 751-758. https://doi.org/10.15585/mmwr.mm6924e1 (2020).

66. Gilmore, B. et al. Community engagement for COVID-19 prevention and control: a rapid evidence synthesis. BMJ Glob. Heal. 5(10), 3188. https://doi.org/10.1136/bmjgh-2020-003188 (2020).

67. Crouse, Q. S. Crisis and emergency risk communication in a pandemic: a model for building capacity and resilience of minority communities. Health Promot Pract. 9 (4 Suppl), 18S-25S. https://doi.org/10.1177/1524839908324022 (2008).

68. Schoch-Spana, M. et al. The public's role in COVID-19 vaccination: Human-centered recommendations to enhance pandemic vaccine awareness, access, and acceptance in the United States. Vaccine. https://doi.org/10.1016/j.vaccine.2020.10.059 (2020).

69. Campo, R., George, S., Gunter, C., et al. COVID-19 Vaccination Communication: Applying Behavioral and Social Science to Address Vaccine Hesitancy and Foster Vaccine Confidence. Bethesda, Maryland (2020).

70. Calvillo, D. P., Ross, B. J., Garcia, R. J. B., Smelter, T. J. \& Rutchick, A. M. Political ideology predicts perceptions of the threat of COVID-19 (and susceptibility to fake news about it). Soc. Psychol. Personal Sci. 11(8), 1119-1128. https://doi.org/10.1177/19485 50620940539 (2020).

71. Loomba, S., de Figueiredo, A., Piatek, S. J., de Graaf, K. \& Larson, H. J. Measuring the impact of COVID-19 vaccine misinformation on vaccination intent in the UK and USA. Nat. Hum. Behav. 5(3), 337-348. https://doi.org/10.1038/s41562-021-01056-1 (2021).

72. Gollust, S. E., Fowler, E. F. \& Niederdeppe, J. Television news coverage of public health issues and implications for public health policy and practice. Annu. Rev. Public Heal. 40, 167-185. https://doi.org/10.1146/annurev-publhealth (2019).

73. Simonov, A., Sacher, S., Dubé, J.-P., \& Biswas, S. The Persuasive Effect of Fox News: Non-Compliance with Social Distancing During the Covid-19 Pandemic. Cambridge, MA (2020). https://doi.org/10.3386/w27237

74. Ratzan, S., Schneider, E. C., Hatch, H. \& Cacchione, J. Missing the point-how primary care can overcome Covid-19 vaccine. Hesitancy. 384(25), e100. https://doi.org/10.1056/NEJMP2106137 (2021).

75. Hassan, A. \& Weiland, N. Some mass vaccination sites in U.S. close as demand begins to fall. The New York Times. https://www. nytimes.com/2021/04/23/us/some-mass-vaccination-sites-in-us-close-as-demand-begins-to-fall.html (2021). Accessed April 26, 2021.

76. Shah, P. D. et al. Pharmacies versus doctors' offices for adolescent vaccination. Vaccine. 36(24), 3453-3459. https://doi.org/10. 1016/j.vaccine.2018.04.088 (2018).

77. Beal, J. L., Kadakia, N. N., Reed, J. B. \& Illingworth Plake, K. S. Pharmacists' impact on older adults' access to vaccines in the United States. Vaccine. 38(11), 2456-2465. https://doi.org/10.1016/j.vaccine.2020.01.061 (2020).

78. United Nations Department of Economic and Social Affairs. World Urbanization Prospects: The 2018 Revision. United Nations Library (2019). https://doi.org/10.18356/b9e995fe-en

79. US Census Bureau. Metropolitan and Micropolitan Statistical Areas Totals: 2010-2019. Washington, DC. https://www.census.gov/ data/tables/time-series/demo/popest/2010s-total-metro-and-micro-statistical-areas.html (2020). Accessed April 26, 2021.

80. Larson, H. J., Cooper, L. Z., Eskola, J., Katz, S. L. \& Ratzan, S. Addressing the vaccine confidence gap. Lancet 378(9790), 526-535. https://doi.org/10.1016/S0140-6736(11)60678-8 (2011).

81. Lazarus, J. V. et al. COVID-SCORE: a global survey to assess public perceptions of government responses to COVID-19 (COVIDSCORE-10). PLoS ONE 15(10), e0240011. https://doi.org/10.1371/journal.pone.0240011 (2020).

82. Quinn, S. C., Jamison, A. M. \& Freimuth, V. Communicating effectively about emergency use authorization and vaccines in the COVID-19 pandemic. Am. J. Public Health. 111(3), 355-358. https://doi.org/10.2105/AJPH.2020.306036 (2021).

83. Freimuth, V. S., Musa, D., Hilyard, K., Quinn, S. C. \& Kim, K. Trust during the early stages of the 2009 H1N1 pandemic. J. Health Commun. 19(3), 321-339. https://doi.org/10.1080/10810730.2013.811323 (2014).

84. Quinn, S. C. et al. Exploring communication, trust in government, and vaccination intention later in the $2009 \mathrm{H} 1 \mathrm{~N} 1$ pandemic: results of a national survey. Biosecur. Bioterror. 11(2), 96-106. https://doi.org/10.1089/bsp.2012.0048 (2013).

85. Karafillakis, E. \& Larson, H. J. The benefit of the doubt or doubts over benefits? a systematic literature review of perceived risks of vaccines in European populations. Vaccine. 35(37), 4840-4850. https://doi.org/10.1016/j.vaccine.2017.07.061 (2017).

86. Larson, H. J., Paterson, P. B. \& Erondu, N. The globalization of risk and risk perception. Drug Saf. 35(11), 1053-1059. https://doi. org/10.1007/bf03261991 (2012).

87. Schmid, P., Rauber, D., Betsch, C., Lidolt, G. \& Denker, M. L. Barriers of influenza vaccination intention and behavior-a systematic review of influenza vaccine hesitancy, 2005-2016. PLoS One. 12(1), 29. https://doi.org/10.1371/journal.pone.0170550 (2017).

88. Strategic Advisory Group of Experts on Immunization (SAGE). Report of the SAGE Working Group on Vaccine Hesitancy. Geneva. https://www.who.int/immunization/sage/meetings/2014/october/1_Report_WORKING_GROUP_vaccine_hesitancy_final.pdf (2021). Accessed April 28, 2021.

89. Allen, J. D., Abuelezam, N. N., Rose, R. \& Fontenot, H. B. Factors associated with the intention to obtain a COVID-19 vaccine among a racially/ethnically diverse sample of women in the USA. Transl. Behav. Med. 11(3), 785-792. https://doi.org/10.1093/ tbm/ibab014 (2021).

90. US Census Bureau. 2019 American Community Survey Single-Year Estimates. https://www.census.gov/newsroom/press-kits/ 2020/acs-1year.html (2020). Accessed October 1, 2021.

\section{Author contributions}

A.E. and J.V.L. conceived the study. S.C.R. and K.R. contributed to study design. S.H.K. oversaw data collection. K.W. and T.M.W. contributed to analysis and manuscript drafting. L.R. provided research and editorial support. All authors contributed to survey questionnaire development and manuscript review.

\section{Competing interests}

The authors declare no competing interests.

\section{Additional information}

Supplementary Information The online version contains supplementary material available at https://doi.org/ 10.1038/s41598-021-00794-6.

Correspondence and requests for materials should be addressed to J.V.L.

Reprints and permissions information is available at www.nature.com/reprints. 
Publisher's note Springer Nature remains neutral with regard to jurisdictional claims in published maps and institutional affiliations.

(c) (i) Open Access This article is licensed under a Creative Commons Attribution 4.0 International License, which permits use, sharing, adaptation, distribution and reproduction in any medium or format, as long as you give appropriate credit to the original author(s) and the source, provide a link to the Creative Commons licence, and indicate if changes were made. The images or other third party material in this article are included in the article's Creative Commons licence, unless indicated otherwise in a credit line to the material. If material is not included in the article's Creative Commons licence and your intended use is not permitted by statutory regulation or exceeds the permitted use, you will need to obtain permission directly from the copyright holder. To view a copy of this licence, visit http://creativecommons.org/licenses/by/4.0/.

(C) The Author(s) 2021, corrected publication 2021 